\title{
Changes in protease inhibitors after acute myocardial infarction
}

\author{
J. A. N. RENNIE, G. P. M. CRAWFORD, AND D. OGSTON \\ From the Department of Medicine, University of Aberdeen
}

SYNOPSIS Plasma levels of fibrinogen, $\alpha_{1}$-antitrypsin, $\alpha_{2}$-macroglobulin, antithrombin III, and $\mathrm{Cl}$ inactivator were measured serially for 10 days in 11 patients after acute myocardial infarction. Both fibrinogen and $\alpha_{1}$-antitrypsin rose markedly to reach peak levels 5-7 days after infarction while $\mathrm{Cl}$ inactivator levels rose slowly with the highest observed mean level on the 10th postinfarction day. Neither antithrombin III nor $a_{2}$-macroglobulin changed significantly after myocardial infarction. No relationship between $\mathrm{Cl}$ inactivator levels and either fibrinogen or $\alpha_{1}$-antitrypsin was found in a study of 30 patients with a variety of disorders while fibrinogen and $\alpha_{1}$-antitrypsin levels were significantly correlated.

Myocardial infarction is followed by changes in a number of serum proteins including components of the haemostatic mechanism: an increase in the level of antiplasmin activity in the immediate postinfarction period has been described by a number of investigators (Bennett et al, 1967; Tsitouris et al, 1967). Four protease inhibitors have been established as having antiplasmin activity- $a_{2}$-macroglobulin (Ganrot, 1967), $\alpha_{1}$-antitrypsin (Rimon et al, 1966), antithrombin III (Highsmith and Rosenberg, 1974), and $\mathrm{Cl}$ inactivator (Ratnoff et al, 1969). We report a study of the changes in these protease inhibitors and fibrinogen over the days following acute myocardial infarction.

\section{Methods}

$\alpha_{2}$-Macroglobulin, $\alpha_{1}$-antitrypsin, antithrombin III, and $\mathrm{Cl}$ inactivator levels were measured by single radial immunodiffusion (Mancini et al, 1965) using reagents obtained from Hoechst Pharmaceuticals, Hounslow, Middlesex. Standard Human Serum, Stabilized and Protein Standard Plasma, both obtained from Hoechst Pharmaceuticals, were used for standardization of $\alpha_{2}$-macroglobulin and of $\alpha_{1}$-antitrypsin and antithrombin III immunoplates respectively. For the standardization of $\mathrm{Cl}$ inactivator a plasma pool from $\mathbf{2 0}$ healthy young men was taken as $100 \%$.

Fibrinogen was assayed in plasma by the method of Ratnoff and Menzie (1951) as modified by Ogston and Ogston (1966).

Received for publication 4 December 1975

\section{Patients}

Eleven men aged 36 to 63 (mean 50) years who had sustained a myocardial infarction and did not subsequently develop a deep-vein thrombosis were studied. The diagnosis was established by unequivocal electrocardiographic appearances together with serial changes in the serum aspartate aminotransferase level. The initial venous blood sample was obtained within 24 hours of the onset of symptoms of infarction (day 1), and further samples were withdrawn on days $2,3,5,6$ to 8 , and 10 . All patients received $100 \mu \mathrm{Ci}{ }^{125}$ I-fibrinogen intravenously 5 to 12 hours after admission for the detection of deep venous thrombosis using the criteria of Kakkar et al (1970). Those patients who developed a deep-vein thrombosis were excluded from the study.

A further 30 patients were selected for measurement of their plasma level of fibrinogen, $a_{1}$-antitrypsin, and $\mathrm{Cl}$ inactivator. A few had no detectable abnormality, and the remainder were suffering from a variety of infective, neoplastic, and degenerative diseases.

\section{Results}

After myocardial infarction the mean plasma fibrinogen concentration rose to approximately twice the initial level, reaching a peak on day 7 . In some patients the peak level was reached by day 5 , in others as late as day 10. $a_{1}$-Antitrypsin levels showed almost parallel changes (figure) with the highest mean level on day 5 after infarction. In con- 


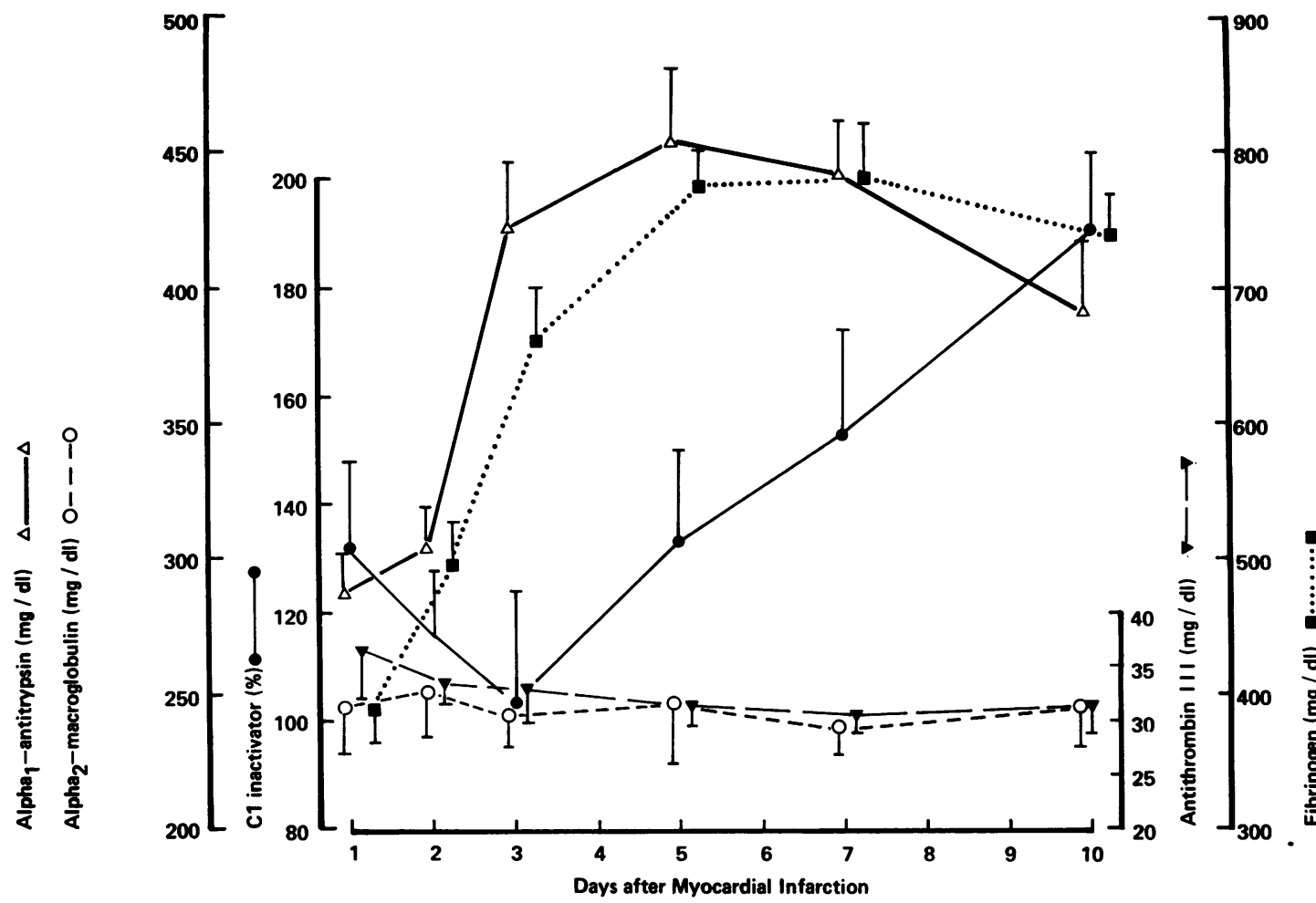

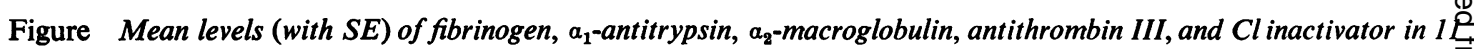
patients after myocardial infarction.

trast, the $\mathrm{Cl}$ inactivator level fell until day 3 , this fall being followed by a progressive increase, the highest mean level being found on the 10th postmyocardial infarction day. Further assays beyond that time were not made. The $\alpha_{2}$-macroglobulin level did not alter significantly and showed no trend in the postinfarction period. While the mean antithrombin III concentration showed a small fall from the initial reading on day 1 , none of the differences from that level reached statistical significance.

Thirty patients with a variety of disorders had a single assay of their plasma fibrinogen, $a_{1}$-antitrypsin, and $\mathrm{Cl}$ inactivator. The correlation between fibrinogen and $\alpha_{1}$-antitrypsin levels $(r=$ $+0.7099)$ was highly significant $(P<0.001)$, while neither that between $\mathrm{Cl}$ inactivator and fibrinogen $(\mathrm{r}=+0.2141)$ nor that between $\mathrm{Cl}$ inactivator and $\alpha_{1}$-antitrypsin $(r=+0.2912)$ reached statistical significance $(\mathrm{P}>0 \cdot 1)$.

\section{Discussion}

During the course of a variety of disease processes and after injury alterations occur in a number o $\frac{\bar{s}}{\tilde{S}}$ serum proteins; these have been termed acute phase reactants (Kelley, 1952) and include fibrinogen, $\alpha_{1} \frac{\hat{\rho}}{0}$ antitrypsin, and ceruloplasmin. An acute phase reaction occurs after myocardial infarction; thẹ. changes in fibrinogen are well documented (Meyers? 1948; Losner et al, 1954; Bennett et al, 1967), and a rise in $a_{1}$-antitrypsin has also been observed (Bachmann et al, 1968).

In the present study we have confirmed the marked. rise in both fibrinogen and $\alpha_{1}$-antitrypsin in the day following a myocardial infarction and have ex amined the changes in other plasma protease in 0 hibitors. In contrast to the finding of McBean et at (1974), we found no increase in the level of $\alpha_{2}$ J macroglobulin in the immediate postinfarction period. It has been claimed that antithrombin IIF levels are reduced after thrombotic episodes, in $\stackrel{\infty}{\rightarrow}$ cluding myocardial infarction (von Kaulla ando von Kaulla, 1967), as a result of consumption. Oū results show a decline after infarction although none्ह of the differences from the initial postinfarction reading was significant. $\mathrm{Cl}$ inactivator, an $\alpha_{2} \mathrm{O}$ neuraminoglycoprotein, has inhibitory activity off 
$\mathrm{Cl}$ esterase and a number of components of the coagulation and fibrinolytic systems including plasmin, activated factor XII, and activated factor XI. Levels of $\mathrm{Cl}$ inactivator in disease states other than hereditary angioedema have received little attention. However, Donaldson (1966) observed a rise in the inhibitor level in acute rheumatic fever, a disorder associated with a rise in acute phase reactants. We have noted a rise in $\mathrm{Cl}$ inactivator levels after myocardial infarction, but the time scale of the changes differs from those in $\alpha_{1}$-antitrypsin and fibrinogen levels (figure). Further, in a study of patients with a variety of diseases a high positive correlation between fibrinogen and $\alpha_{1}$-antitrypsin was detected but no correlation was found between $\mathrm{Cl}$ inactivator and either fibrinogen or $\alpha_{1}$-antitrypsin levels. We concluded that although $\mathrm{Cl}$ inactivator levels rise markedly after acute myocardial infarction, the behaviour of this protein does not follow the pattern of changes observed in acute phase reactant proteins.

The significance of changes in protease inhibitors after myocardial infarction is not clear. The changes in $a_{1}$-antitrypsin closely parallel those of total antiplasmin activity after an infarction, suggesting that this inhibitor is principally responsible for the rise in antiplasmin activity in this situation. It is possible that the rises in $\alpha_{1}$-antitrypsin and fibrinogen might contribute to the increased liability to venous thrombosis after a myocardial infarction.

\section{References}

Bachmann, G. W., Weiss, M. E., and Rapp, W. (1968). Differenzierte quantitative Serumeiweißbestimmungen im Ablauf des Herzinfarktes. Schweiz. med. Wschr., 98, 18251828.

Bennett, N. B., Ogston, C. M., and Ogston, D. (1967). Studies on the blood fibrinolytic enzyme system following acute myocardial infarction. Clin. Sci., 32, 27-37.

Donaldson, V. H. (1966). Serum inhibitor of C'l-esterase in health and disease. J. Lab. clin. Med., 68, 369-382.

Highsmith, R. F. and Rosenberg, R. D. (1974). The inhibition of human plasmin by human antithrombin-heparin cofactor. J. biol. Chem., 249, 4335-4338.

Kakkar, V. V., Nicolaides, A. N., Renney, J. T. G., Friend, J. R., and Clarke, M. B. (1970). ${ }^{125}$ I-labelled fibrinogen test adapted for routine screening for deep-vein thrombosis. Lancet, 1, 540-542.

Kelley, V. C. (1952). Acute phase reactants. I. Serum nonglucosamine polysaccharides in patients with rheumatic fever and related conditions. J. Pediat., 40, 405-412.

Losner, S., Volk, B. W., and Wilensky, N. D. (1954). Fibrinogen concentration in acute myocardial infarction. Arch. intern. Med., 93, 231-245.

McBean, L. D., Smith, J. C., Jr., Berne, B. H., and Halsted, J. A. (1974). Serum zinc and alpha $a_{2}$-macroglobulin concentration in myocardial infarction, decubitus ulcer, multiple myeloma, prostatic carcinoma, Down's syndrome and nephrotic syndrome. Clin. chim. Acta, 50, 43-51.

Mancini, G., Carbonara, A. O., and Heremans, J. F. (1965). Immunochemical quantitation of antigens by single radial immunodiffusion. Immunochemistry, 2, 235-254.

Meyers, L. (1948). Blood fibrinogen in myocardial infarction. Arch. intern. Med., 82, 419-421.

Ogston, C. M. and Ogston, D. (1966). Plasma fibrinogen and plasminogen levels in health and in ischaemic heart disease. J. clin. Path., 19, 352-356.

Ratnoff, O. D. and Menzie, C. (1951). A new method for the determination of fibrinogen in small samples of plasma. J. Lab. clin. Med., 37, 316-320.

Ratnoff, O. D., Pensky, J., Ogston, D., and Naff, G. B. (1969). The inhibition of plasmin, plasma kallikrein, plasma permeability factor, and the C'lr subcomponent of the first component of complement by serum C'l esterase inhibitor. J. exp. Med., 129, 315-331.

Rimon, A., Shamash, Y., and Shapiro, B. (1966). The plasmin inhibitor of human plasma. IV. Its action on plasmin, trypsin, chymotrypsin, and thrombin. J. biol. Chem., 241, 5102-5107.

Tsitouris, G., Stathopoulou, R., and Tsevrenis, I. (1967). Serum inhibition of plasmin and of plasminogen activation in thrombotic diseases. $J$. atheroscler. Res., 7, 425-433.

von Kaulla, E. and von Kaulla, K. N. (1967). Antithrombin III and diseases. Amer. J. clin. Path., 48, 69-80. 